\title{
The route of hysterectomy: a comparative study between abdominal hysterectomy (AH), non descent vaginal hysterectomy (NDVH), and laparoscopic assisted vaginal hysterectomy (LAVH)
}

\author{
Prashaant Uikey $^{1}$, Trupti M. Wankhede ${ }^{1 *}$, Megha P. Tajne ${ }^{2}$
}

\begin{abstract}
${ }^{1}$ Department of Obstetrics and Gynecology, Indira Gandhi Government Medical College, Nagpur, Maharashtra, India ${ }^{2}$ Department of Anaesthesia, NKP Salve Institute of Medical Sciences, Nagpur, Maharashtra, India
\end{abstract}

Received: 18 July 2018

Accepted: 28 August 2018

\author{
*Correspondence: \\ Dr. Trupti M. Wankhede, \\ E-mail: trupti.w19@gmail.com
}

Copyright: (c) the author(s), publisher and licensee Medip Academy. This is an open-access article distributed under the terms of the Creative Commons Attribution Non-Commercial License, which permits unrestricted non-commercial use, distribution, and reproduction in any medium, provided the original work is properly cited.

\section{ABSTRACT}

Background: Hysterectomy is the most common operation performed by the gynaecologist. The uterus can be removed using any of the technique and approaches, including abdominal, vaginal, laparoscopic. There are no formal guidelines available regarding the most appropriate route of hysterectomy. Hence, a comparison of the clinical results of the three routes of hysterectomy is needed.

Methods: a prospective study was performed at Indira Gandhi government medical college Nagpur between September 2015- October 2017, among 150 women indicated to undergo hysterectomy for benign and mobile uterine conditions. They were assigned 50 each to three routes of hysterectomy (abdominal, non-descent vaginal hysterectomy and Laparoscopic assisted vaginal hysterectomy). Outcome measures including operating time, blood loss, fall in haemoglobin, intra-operative complications, duration of analgesia, VAS score, hospital stay and postoperative morbidity were assessed and compared between the three groups.

Results: Fibroid uterus $(65.33 \%)$, was the commonest indication for hysterectomy. As far as operating time, intraoperative blood loss, fall in haemoglobin, duration of analgesia, VAS score and hospital stay P Value was significant among the three group. Incidence of complications was least in the NDVH group.

Conclusions: In developing country like India with poor health care resources, scarcity of beds and non-availability of sophisticated equipment NDVH offers a distinctive advantage over other route of hysterectomy and should be the route of choice for benign uterine conditions.

Keywords: Abdominal hysterectomy (AH), Hysterectomy, Laparoscopic assisted vaginal hysterectomy (LAVH), Non-descent vaginal hysterectomy (NDVH)

\section{INTRODUCTION}

Hysterectomy is the surgical removal of uterus. Hysterectomy is the most common operation performed by the gynecologist, and it is the second most common major surgical procedure after cesarean section. ${ }^{1,2,3}$ There are many indications for hysterectomy like symptomatic or growing uterine leiomyomas $(40.7 \%)$, adenomyosis, abnormal uterine bleeding, chronic pelvic pain, endometriosis $\left(17.7 \%\right.$ )and prolapse uterus $(14.5 \%)^{4}$. The uterus can be removed using any of a variety of techniques and approaches, including abdominal, vaginal, laparoscopic or robotic surgery.

The various factors that may influence the route of hysterectomy for benign causes include the size of the vagina, the size and shape of uterus; accessibility to the uterus; extent of extrauterine disease; the need for 
concurrent procedures; surgeon training and experience; available hospital technology, devices and support; emergency or scheduled cases; and preference of the patient. ${ }^{4}$ The abdominal route to hysterectomy is most popular and remains the route of choice in dealing with large size uterus, ovarian masses and gynaecological malignancies. Though abdominal hysterectomy has shorter operating time, but it results in longer duration of hospital stay and return to normal activity, larger drop in haemoglobin, more intraoperative blood loss and wound or abdominal wall infections.

Vaginal route was used initially for prolapse of uterus but now-a-days it is widely utilized for benign conditions of uterus like abnormal uterine bleeding, fibroid, etc with non-descent of uterus. Ample evidence shows that the vaginal approach results in lower morbidity, less pain, more rapid recovery, more rapid return to normal activities, consumption of fewer health care resources, and a host of other benefits. But limitations for vaginal route of hysterectomy are a narrow pubic arch, a narrow vagina, an undescended immobile uterus, nulliparity, prior cesarean delivery enlarged uterus and adnexal pathology.

LAVH has become a major alternative to conventional abdominal hysterectomy, with patients often opting for a laparoscopic approach for cosmetic and faster recuperative reasons. LAVH offers superior tissue image and anatomic view of the abdomino-pelvic cavity, facilitates meticulous hemostasis, reduces the morbidity associated with laparotomy, and performing adnexal surgery, ureterolysis, retroperitoneal dissection and also excision of endometriosis. ${ }^{2}$ These advantages make laparoscopic procedures more acceptable than abdominal techniques. Laparoscopic surgeries have long learning curve and need sophisticated instruments and expertise.

Ideal method of hysterectomy should have low morbidity, low health care costs, less operating time, less duration of hospital stay, it should be minimally invasive and there should be better patient satisfaction.

It is said that the various routes of hysterectomy are not competitive procedures, but each has its own place in the operative armamentarium of the gynaecologist.

As no procedure is ideal present study aims to evaluate and compare clinical outcomes of three different routes of hysterectomy (AH, NDVH, LAVH).

The aim is to study and compare the clinical results of three routes of hysterectomy namely Abdominal (AH), Non-descent vaginal hysterectomy (NDVH) and Laparoscopic assisted vaginal hysterectomy (LAVH) and the objectives are to study and compare the intraoperative parameters like operating time for surgery, intraoperative blood loss and intraoperative visceral injuries; to study and compare postoperative complications like febrile morbidity, urinary tract infections, pain score on day3, requirement of blood transfusion and length of hospital stay with each route and to compare the comfort of the patient in terms of post operative requirement of analgesia with each route.

\section{METHODS}

A prospective study was conducted at Indira Gandhi government medical college Nagpur for a period of 2 years (from September 2015-October 2017) to compare the three routes of hysterectomy i.e. AH, NDVH and LAVH with regards to its intra-operative and postoperative outcomes.

A total 150 patients attending gynaecology OPD of this institution indicated for hysterectomy who consented to participate in the study after fulfilling inclusion and exclusion criteria were enrolled for the study. Each group comprised of 50 patients who were operated by three different routes of hysterectomy, after adjusting demographic and co-morbid conditions. The three groups were as follows:

- Group A-Abdominal hysterectomy group (AH).

- Group B-Non-descent vaginal hysterectomy group (NDVH).

- Group C-Laparoscopic assisted vaginal hysterectomy group (LAVH).

\section{Inclusion criteria}

- Benign condition of uterus.

- Uterus size $<14$ weeks.

- $\quad$ Patients age $>30$ years $<70$ years

- Mobile uterus.

\section{Exclusion criteria}

- $\quad$ Size of uterus $>14$ weeks.

- Patient with gynecology malignancy.

- Pervious cesarean sections.

- Patients with adnexal masses.

- Prolapse of uterus.

- $\quad$ BMI $>35 \mathrm{~kg} / \mathrm{m}^{2}$.

Detailed history was elicited, and a thorough examination was conducted which included complete physical as well as pelvic and rectal examination and the findings were jotted down on the pre-designed case proformas. Routine preoperative investigations were done. Patients were subjected to hysterectomy only if $\mathrm{Hb} \%$ was $\geq 10 \mathrm{gm} \%$.

Complete evaluation was done by anaesthetist before deciding the type of anaesthesia. Hysterectomies by all these three routes were performed as per present standard hospital protocols and steps. Intra operative parameters like operating time, blood loss and bladder/ bowel injury and post-operative parameters viz, febrile morbidity, urinary tract infections, requirement of analgesia, pain 
score on day 3 was assessed by visual analogue scale and hospital stay were evaluated and compared. Operating time for abdominal hysterectomy was calculated from the start of skin incision to the closure of the skin incision and for vaginal hysterectomy from the start of incision at cervicovaginal junction to the closure of vault. For LAVH operating time was calculated from the insertion of veres needle to closure of port insertion site.

Blood loss was calculated by noting the number of Mops used along with the blood collected in the suction bottles during surgery. Same antibiotics and analgesics were given to all subjects post-operatively. Post-op day $3 \mathrm{Hb} \%$ was measured and fall in haemoglobin was noted. Post operatively, all patients were meticulously followed up. The comfort of the patient was noted by post-op analgesia requirement which was based on visual analogue scale (VAS). Post-operative complications like fever, urinary tract infection, vaginal cuff cellulites, and abdominal wound infection was noted. The wound of the patients of $\mathrm{AH}$ group were inspected for any induration, redness and wound discharge on day 5 and were discharged on day 7 after suture removal was done. Patients of NDVH were discharged on day 4 after per speculum examination of the vaginal vault. LAVH were discharged on day 3 once they were fit to be discharge and they were followed up on day 5 for wound examination and suture removal.

\section{Statistical analysis}

The three routes of hysterectomies were compared for predetermined intraoperative and postoperative parameters and results were analysed by ANOVA test, $t$ test by using SPSS software.

\section{RESULTS}

The $p$ value of age, parity and BMI was $>0.05$, thus these parameters were not significant. Thus, all the three group were comparable.

Table 1: Mean age, parity and BMI of cases in each group.

\begin{tabular}{|lllllll|}
\hline Group & Mean age (years) \pm SD & p-value & Mean parity \pm SD & p-value & Mean BMIISD & p-value \\
\hline Group A AH & $45.0 \pm 4.5$ & & $2.8 \pm 1.3$ & $0.26 \mathrm{NS}$ & $21.68 \pm 0.60$ & $0.81 \mathrm{NS}$ \\
\hline Group B NDVH & $44.7 \pm 4.7$ & 0.26 & $2.8 \pm 1.0$ & & $21.66 \pm 0.97$ & \\
\hline Group C LAVH & $43.7 \pm 2.8$ & Hence, NS & $2.5 \pm 0.8$ & & $21.77 \pm 1.09$ \\
\hline
\end{tabular}

*ANOVA test.

Table 2: Indication wise distribution of cases in group.

\begin{tabular}{|c|c|c|c|c|}
\hline Indications & $\begin{array}{l}\text { Group A } \\
\mathbf{A H} \\
\mathbf{N}=\mathbf{5 0}\end{array}$ & $\begin{array}{l}\text { Group B } \\
\text { NDVH } \\
\mathbf{N}=\mathbf{5 0}\end{array}$ & $\begin{array}{c}\text { Group C } \\
\text { LAVH } \\
\mathbf{N}=50\end{array}$ & $\begin{array}{l}\text { Total } \\
\mathbf{N}=150\end{array}$ \\
\hline Fibroid & 26 & 37 & 35 & 98 \\
\hline Adenomyosis & 9 & 3 & 3 & 15 \\
\hline $\begin{array}{l}\text { Endometrial } \\
\text { hyperplasia }\end{array}$ & 0 & 2 & 1 & 3 \\
\hline AUB & 15 & 8 & 11 & 33 \\
\hline
\end{tabular}

The most common indication for hysterectomy was fibroid uterus $(65.33 \%)$ and the second most common indication was Abnormal uterine bleeding.

Table 3: Uterine size wise distribution in each group.

\begin{tabular}{|lllll|}
\hline $\begin{array}{l}\text { Size of } \\
\text { uterus }\end{array}$ & Group A & Group B & Group C & Total \\
(weeks) & $\mathbf{N}=50$ & $\mathbf{N}=\mathbf{5 0}$ & $\mathbf{N}=50$ & $\mathbf{N}=\mathbf{1 5 0}$ \\
\hline$\leq 8$ weeks & 10 & 6 & 7 & 23 \\
\hline 8 weeks & 40 & 44 & 43 & 127 \\
\hline
\end{tabular}

127 cases $(84.6 \%)$ operated had uterus size of 8-14 weeks. 44(88\%) cases had uterus size between 8-14 weeks in NDVH followed by $43(86 \%)$ in LAVH group and $40(80 \%)$ in abdominal group.
Thus, the three groups were comparable with respect to their uterine size.

\section{Intra operative parameters}

The mean operative time required was statistically significant ( $\mathrm{p}$ value $<0.05$ ). the operative time required for LAVH $(98.3 \pm 5.3)$ was the longest and shortest for $\mathrm{AH}$ $(64.2 \pm 5.8)$. The mean blood loss was highest $328 \pm 70.1$ in abdominal group and lowest $120.5 \pm 43.7$ in the laparoscopic assisted vaginal hysterectomy group. The fall in haemoglobin postoperatively was $1.086 \pm 0.54$ in the abdominal group, $0.836 \pm 0.49$ in the non-descent vaginal hysterectomy group and $0.534 \pm 0.29$ in the laparoscopy group.

The mean operating time in present study was in the following order: $\mathrm{LAVH}>\mathrm{NDVH}>\mathrm{TAH}$. The blood loss in LAVH group was less and statistically significant compared to abdominal and NDVH group ( $\mathrm{p}$ value $<0.0001)$.

Postoperatively the fall in the haemoglobin was seen in the following order $\mathrm{AH}>\mathrm{NDVH}>\mathrm{LAVH}$. Thus, $\mathrm{AH}$ was associated with more intra-operative blood loss as compared to other route of hysterectomy. 
Table 4: Mean operative time, mean blood loss and mean fall in haemoglobin in each group.

\begin{tabular}{|c|c|c|c|c|c|c|}
\hline Group & $\begin{array}{l}\text { Mean operative } \\
\text { time } \pm \text { SD (minutes) }\end{array}$ & P-value & $\begin{array}{l}\text { Mean blood } \\
\text { loss }(\mathrm{ml}) \pm \mathrm{SD}\end{array}$ & P-value & $\begin{array}{l}\text { Mean fall in haemoglobin } \\
(\mathrm{gm} \%) \pm \mathrm{SD}\end{array}$ & P-value \\
\hline Group A AH & $64.2 \pm 5.8$ & \multirow{3}{*}{$<0.05 \mathrm{~S}$} & $328.0 \pm 70.1$ & $<0.0001 \mathrm{~S}$ & $1.086 \pm 0.54$ & $0.000 \mathrm{~S}$ \\
\hline Group B NDVH & $67.4 \pm 7.9$ & & $192.0 \pm 21.1$ & & $0.836 \pm 0.49$ & \\
\hline Group C LAVH & $98.3 \pm 5.3$ & & $120.5 \pm 43.7$ & & $0.534 \pm 0.29$ & \\
\hline
\end{tabular}

Table 5: Comparison of operative time, blood loss and mean fall in haemoglobin between two groups.

\begin{tabular}{|lllllll|}
\hline Group & $\begin{array}{l}\text { Mean operative } \\
\text { time } \pm \text { SD (minutes) }\end{array}$ & P-value & $\begin{array}{c}\text { Mean blood } \\
\text { loss }(\mathrm{ml}) \pm \text { SD }\end{array}$ & P value & $\begin{array}{c}\text { Mean fall in Hb } \\
\text { (gm \%) } \pm \text { SD }\end{array}$ & P-value \\
\hline AH & $64.2 \pm 5.8$ & \multirow{2}{*}{$0.02 \mathrm{~S}$} & $328.0 \pm 70.1$ & $0.02 \mathrm{~S}$ & $1.086 \pm 0.54$ & $0.0172 \mathrm{~S}$ \\
\hline $\mathrm{NDVH}$ & $67.4 \pm 7.9$ & & $192.0 \pm 21.1$ & & $0.836 \pm 0.49$ & \\
\hline $\mathrm{NDVH}$ & $67.4 \pm 7.9$ & \multirow{2}{*}{$<0.0001 \mathrm{~S}$} & $192.0 \pm 21.1$ & $<0.0001 \mathrm{~S}$ & $0.836 \pm 0.49$ & $0.0003 \mathrm{~S}$ \\
\hline LAVH & $98.3 \pm 5.3$ & & $120.5 \pm 43.7$ & & $0.534 \pm 0.29$ & \\
\hline LAVH & $98.3 \pm 5.3$ & \multirow{2}{*}{$<0.0001 \mathrm{~S}$} & $120.5 \pm 43.7$ & $<0.0001 \mathrm{~S}$ & $0.534 \pm 0.29$ & $<0.0001 \mathrm{~S}$ \\
\hline AH & $64.2 \pm 5.8$ & & $328.0 \pm 70.1$ & & $1.086 \pm 0.54$ & \\
\hline
\end{tabular}

*T test

In present study authors did not get any cases of bladder, bowel or ureteric injury. 6 cases of $\mathrm{AH}, 1$ case of NDVH and 2 cases of LAVH required blood transfusion intraoperatively due to haemorrhage.

Table 6: Intraoperative complications in each group.

\begin{tabular}{|lll|l|}
\hline Complications & $\begin{array}{l}\text { Group A } \\
\text { AH }\end{array}$ & $\begin{array}{l}\text { Group B } \\
\text { NDVH }\end{array}$ & $\begin{array}{l}\text { Group C } \\
\text { LA VH }\end{array}$ \\
\hline $\begin{array}{l}\text { Bladder, bowel, } \\
\text { ureteric injury }\end{array}$ & 0 & 0 & 0 \\
\hline Blood transfusion & 6 & 1 & 2 \\
\hline
\end{tabular}

7 cases of abdominal hysterectomy, 1 case of NDVH and 2 cases of LAVH had febrile morbidity.

Abdominal wound gape was seen in 2 cases and wound discharge was present in 3 cases of abdominal hysterectomy.

No other complications were noted in any of the three groups.
Table 7: Postoperative morbidity in each group.

\begin{tabular}{|lll|l|}
\hline Complications & Group A & $\begin{array}{l}\text { Group B } \\
\text { NDVH }\end{array}$ & $\begin{array}{l}\text { Group C } \\
\text { LA VH }\end{array}$ \\
\hline Fever & 7 & 1 & 2 \\
\hline $\begin{array}{l}\text { Abdominal wound } \\
\text { gape }\end{array}$ & 2 & $\begin{array}{l}\text { Not } \\
\text { applicable }\end{array}$ & 0 \\
\hline Urinary tract infection & 0 & 0 & 0 \\
\hline Urinary retention & 0 & 0 & 0 \\
\hline $\begin{array}{l}\text { Wound discharge } \\
\text { Vault hematoma/ }\end{array}$ & 3 & 0 & 0 \\
\hline $\begin{array}{l}\text { Vault cellulitis } \\
\text { Reactionary }\end{array}$ & 0 & 0 & 0 \\
\hline haemorrhage & 0 & 0 & 0 \\
\hline
\end{tabular}

\section{Post-operative parameters}

The patients in the LAVH group required analgesics for $1.52 \pm 0.25$ days which was the least amongst all the three group, had maximum post-operative comfort as inferred from the VAS score and had faster return to their daily activity with least days of hospital stay.

Table 8: Mean duration of analgesic required, mean VAS score on day 3 and mean hospital stay in each group.

\begin{tabular}{|c|c|c|c|c|c|c|}
\hline Group & $\begin{array}{l}\text { Mean analgesics } \\
\text { required (days) } \pm S D\end{array}$ & P-value & $\begin{array}{l}\text { Mean VAS score } \\
\text { on day } \mathbf{3} \pm \mathrm{SD}\end{array}$ & P-value & $\begin{array}{l}\text { Mean hospital } \\
\text { stay } \pm \text { SD }\end{array}$ & P-value \\
\hline Group A AH & $2.64 \pm 0.40$ & \multirow{3}{*}{$<0.05 \mathrm{~S}$} & $5.3 \pm 0.4$ & $<0.0001 \mathrm{~S}$ & $7.9 \pm 3.64$ & $<0.0001 \mathrm{~S}$ \\
\hline Group B NDVH & $2.36 \pm 0.48$ & & $3.1 \pm 0.4$ & & $4.1 \pm 0.30$ & \\
\hline Group C LAVH & $1.52 \pm 0.25$ & & $1.8 \pm 0.4$ & & $3.12 \pm 0.33$ & \\
\hline
\end{tabular}


The duration of analgesia was far less in the LAVH group and was statistically significant than the TAH and NDVH group ( $\mathrm{p}$ value $<0.0001$ ). So, from the above data authors found out that the requirement of analgesia was as follows: $\mathrm{AH}>\mathrm{NDVH}>\mathrm{LAVH}$.

It was found that the VAS score on day 3 was $1.8 \pm 0.4$ in the LAVH group which was significantly lower than the abdominal group $(5.3 \pm 0.4)$ and NDVH group (3.1 \pm 0.4$)$. The difference in the pain rating score amongst the three groups was found to be statistically significant with $\mathrm{p}$ value of $<0.0001$. The study proved that postoperative comfort was very high in LAVH. In present study mean hospital stay for the three routes were as follows: AH $>$ NDVH $>$ LAVH. Hospital stay was shortest for $\mathrm{LAVH}$ and longest for AH.

Table 9: Comparison of analgesia required, VAS score and post-operative hospital stay between two groups.

\begin{tabular}{|c|c|c|c|c|c|c|}
\hline Group & $\begin{array}{l}\text { Analgesics required } \\
\text { mean } \pm \text { SD }\end{array}$ & P-value & $\begin{array}{l}\text { Mean VAS } \\
\text { score } \pm \text { SD }\end{array}$ & P-value & $\begin{array}{l}\text { Post-operative hospital } \\
\text { stay (mean days } \pm \text { SD) }\end{array}$ & P-value \\
\hline $\mathrm{AH}$ & $2.64 \pm 0.40$ & \multirow{2}{*}{$0.04 \mathrm{~S}$} & $5.3 \pm 0.4$ & $<0.0001 \mathrm{~S}$ & $7.90 \pm 3.64$ & $<0.0001 \mathrm{~S}$ \\
\hline NDVH & $2.36 \pm 0.48$ & & $3.1 \pm 0.4$ & & $4.34 \pm 1.98$ & \\
\hline NDVH & $2.36 \pm 0.48$ & \multirow{2}{*}{$<0.0001 \mathrm{~S}$} & $3.1 \pm 0.4$ & $<0.0001 \mathrm{~S}$ & $4.34 \pm 1.98$ & $<0.0001 \mathrm{~S}$ \\
\hline LAVH & $1.52 \pm 0.25$ & & $1.8 \pm 0.4$ & & $3.12 \pm 0.33$ & \\
\hline LAVH & $1.52 \pm 0.25$ & \multirow{2}{*}{$<0.0001 \mathrm{~S}$} & $1.8 \pm 0.4$ & $<0.0001 \mathrm{~S}$ & $3.12 \pm 0.33$ & $<0.0001 \mathrm{~S}$ \\
\hline $\mathrm{AH}$ & $2.64 \pm 0.40$ & & $5.3 \pm 0.4$ & & $7.90 \pm 3.64$ & \\
\hline
\end{tabular}

\section{DISCUSSION}

Hysterectomy are easily the most common elective surgeries in the gynaecology; with Abdominal, Vaginal and Laparoscopic hysterectomy holding their own position in the Gynaecological Universe and certainly not at loggerhead with each other. ${ }^{5}$

Many a times, it is difficult to decide the type of surgery, which depends on the experience of the operating surgeon. The decision should be the optimal one for a given patient under given circumstances.

There are significant differences in the medical and economic outcomes of Abdominal, Vaginal and Laparoscopic-type hysterectomies, the standard of appropriate care should be applied to the choice of surgical route for individual patients. ${ }^{6}$ Hence, now the type of surgical route for hysterectomy is being subjected to more careful scrutiny.

In present study authors found that the maximum number of cases who underwent hysterectomy had age in the range of 40-49 years. Thus, it is obvious that most hysterectomies are done in peri-menopausal age group. The mean parity was 2.8 and the $\mathrm{p}$ value for BMI in three groups was 0.81 which indicates that it was nonsignificant (Table1).

In a study conducted by Sandhyasri $\mathrm{P}$ et al the mean age for $\mathrm{AH}$ was 40.84 years, NDVH was 41.44 years and that in the LAVH group was 44.57 years. $^{7}$

Montefire ED et al conducted an observational prospective study from June to December 2004, the mean parity in their study was $2 \pm 1.6 .^{8}$
In a study conducted by Radhika $\mathrm{Y}$ et al the mean BMI was $21.714,21.512$ and 21.238 in the LAVH, TAH and NDVH group respectively. ${ }^{9}$

Thus, the demographic characteristics i.e. age, parity and BMI of the three group were identical and comparable to other standard studies.

In the present study the most common indications for hysterectomy were fibroid uterus $(65.3 \%)$, which was followed by Abnormal Uterine Bleeding, Adenomyosis (Table 2).

In present study 127 cases $(84.6 \%)$ had uterus size between $8-14$ weeks. 40 cases $(80 \%)$ in the TAH group, 44 cases $(88 \%)$ in the NDVH group and 43 cases $(86 \%)$ in the LAVH group had uterus size more than 8 weeks of gestation. Thus, the three-study groups were comparable with respect to their uterine size (Table 3 ).

In the present study the mean operative time was $64.2 \pm 5.8 \mathrm{~min}, 67.4 \pm 7.9 \mathrm{~min}$ and $98.3 \pm 5.3$ in the TAH, NDVH and LAVH group respectively which was statistically significant. The operative time was longest for LAVH and shortest for TAH (Table 4 and 5).

A randomized prospective comparative study was conducted by Sandhyasri $\mathrm{P}$ et al where the mean operating time in LAVH group was $(124.56 \pm 19.49 \mathrm{~min})$, $(64.14 \pm 10.69 \mathrm{~min})$ in NDVH and $(61.26 \pm 10.49 \mathrm{~min})$ in AH group. The $\mathrm{p}$ value was $<0.05$ which was significant. ${ }^{7}$

Radhika $\mathrm{Y}$ et al conducted an observational prospective study in which included the operating time for LAVH was $128.6 \mathrm{~min}, \mathrm{NDVH}$ was $88.2 \mathrm{~min}$ and $\mathrm{AH}$ was 65.38 
min. The operating time was shortest for TAH and longest by LAVH group. ${ }^{9}$

In the present study mean blood loss was $328.0 \pm 70.1 \mathrm{ml}$, $192.0 \pm 21.1$ and $120.5 \pm 43.7 \mathrm{ml}$ in the AH, NDVH and LAVH group respectively. $\mathrm{P}$ value was $<0.0001$ which was statistically significant (Table 4 and 5).

A retrospective cohort study by Kelly wright et al; the blood loss in the AH group was $333.76 \mathrm{ml}$, in the NDVH group was $143.48 \mathrm{ml}$ and in the LAVH group it was $105.43 \mathrm{ml}$, indicating that the estimated blood loss was greater in the abdominal group than NDVH and LAVH group. ${ }^{10}$

A non-randomized prospective cohort study was conducted by Deshpande $\mathrm{H}$ et al; the blood loss was $138.80 \mathrm{ml}$ in the TAH group, but it was only $41.96 \mathrm{ml}$ in NDVH group. ${ }^{5}$

In a study by Mishra $\mathrm{N}$ et al it was found that the mean blood loss was $145.9 \pm 27.8 \mathrm{ml}$ in LAVH which was significantly less than the TAH group $(202.2 \pm 31.1 \mathrm{ml}) .{ }^{11}$

In a prospective longitudinal comparative study conducted by De Reena et al mean blood loss was 112.92 $\mathrm{ml}$ in NDVH and $97.58 \mathrm{ml}$ in LAVH. ${ }^{12}$

The findings of present study are comparable to all above studies and indicates that blood loss is more and statistically significant in $\mathrm{AH}$ and it is least in $\mathrm{LAVH}$ group. There is also statistically significant difference in the blood loss between NDVH and LAVH group.

In a retrospective analysis by Elessawy $M$ et al the haemoglobin loss was $0.70 \mathrm{~g} / \mathrm{dl}, 1.29 \mathrm{gm} / \mathrm{dl}$ and $1.63 \mathrm{gm} / \mathrm{dl}$ in the $\mathrm{LAVH}, \mathrm{VH}$ and $\mathrm{AH}$ group respectively. ${ }^{13}$

In the present study the mean fall in haemoglobin was $0.534 \pm 0.29 \mathrm{gm} \%, 0.836 \pm 0.49 \mathrm{gm} \%$ and $1.086 \pm 0.54 \mathrm{gm} \%$ in LAVH, NDVH and TAH group respectively (Table 4 and 5). Thus, it is obvious that the fall in haematocrit is more in the abdominal hysterectomy followed by NDVH as compared to LAVH group.

In present study authors did not get any cases of bladder, bowel or ureteric injury. Blood transfusion were required intraoperatively in 6 cases of TAH, 1 case of NDVH and 2 cases of LAVH group (Table 6).

A retrospective study by $\mathrm{McCracken} \mathrm{G}$ et al reported 1 case each of urinary tract injury in the LAVH and TAH group. 1 case of bowel injury was noted in the VH group. Three patients in each of the three-group required blood transfusion. ${ }^{14}$

In a study by Wright $\mathrm{KN}$ et al, they reported 2 cases of organ injury in abdominal group, 1 in vaginal and 1 in laparoscopic group. ${ }^{10}$
In a prospective study by Radhika $\mathrm{Y}$ et al intraoperative no visceral injuries were noted in TAH group, there was 1 case of bladder injury in LAVH group and 1 in NDVH group. ${ }^{9}$

Thus, it is noted that cases of haemorrhage requiring blood transfusion are more in TAH group. Authors did not get any case of visceral injury in present study but from above studies it is obvious that LAVH group tends to have more visceral injuries compared to $\mathrm{AH}$ and $\mathrm{VH}$.

In present study 7 case in the AH group, 2 in LAVH group and $1 \mathrm{NDVH}$ group had fever postoperatively. 2 cases had wound gape and 3 cases had wound discharge in AH group. No cases of wound discharge were seen in LAVH group. Authors did not get any cases of urinary tract infection, vault hematoma and reactionary haemorrhage in any of the group (Table 7).

In a study by Sandhyasri P et al, 6 cases of wound sepsis and 2 cases of vault hematoma were seen in $\mathrm{AH}$ group whereas no cases of wound sepsis or vault hematoma were seen in NDVH and LAVH group. ${ }^{7}$

Moradan $\mathrm{S}$ et al reported 6 cases of urinary tract infection, 3 cases bladder injury, 2 wound infection, and 16 cases had post-operative febrile morbidity in $\mathrm{AH}$ group. One case of urinary tract infection was seen in VH. Laparoscopic and vaginal hysterectomies had the lowest postoperative complication rates. ${ }^{3}$

Thus, TAH is associated with more postoperative morbidity.

In present study the mean duration of analgesics required was $2.64 \pm 0.40,2.36 \pm 0.48$ and $1.52 \pm 0.25$ days in $\mathrm{AH}$, $\mathrm{NDVH}$ and LAVH group respectively, $\mathrm{p}$ value $<0.05$ which was found to be statistically significant (Table 8 and 9). According to study by Schindlbeck et al, need for analgesia was less in LAVH group (1.5 days) compared to VH (2 days) and TAH group (4 days). ${ }^{15}$ A study by Mishra $\mathrm{N}$ et al additional analgesia was required in $7(33 \%)$ cases in the laparoscopic hysterectomy group and 14 cases $(64 \%)$ in the abdominal hysterectomy group ( $\mathrm{p}$ value<0.001). ${ }^{11}$ Hence it can be seen that the need of analgesia is least with LAVH group.

In present study D3 pain score was $5.3 \pm 0.4 \mathrm{~cm}$, $3.1 \pm 0.4 \mathrm{~cm}$ and $1.8 \pm 0.4 \mathrm{~cm}$ in the AH, NDVH and LAVH group respectively. The difference in the pain score rating among the three group was found to be statistically significant with $\mathrm{p}$ value $<0.0001$ (Table 8 and 9). Radhika $\mathrm{Y}$ et al study had D3 pain score of $5.8 \mathrm{cms}$ in TAH group, $3.7 \mathrm{~cm}$ in $\mathrm{VH}$ group and $2.02 \mathrm{~cm}$ in LAVH group. ${ }^{9}$

Deshpande $\mathrm{H}$ et al, measured pain post-operatively on day 1,2,3 and they found that the scores were always higher in the TAH group than the NDVH group. ${ }^{5}$ In a longitudinal study by Mirza $\mathrm{R}$ et al the day 3 pain score was $2.82 \pm 1.147 \mathrm{~cm}$ and $3.41 \pm 1.175 \mathrm{~cm}$ in the $\mathrm{VH}$ and 
TAH group respectively. ${ }^{16}$ Thus, it can be inferred that the postoperative patient comfort is maximum in LAVH followed by NDVH and $\mathrm{AH}$ group.

In the present study the mean post-operative hospital stay was $7.9 \pm 3.64$ in the AH group, $4.1 \pm 0.30$ days in the $\mathrm{NDVH}$ and $3.12 \pm 0.33$ days in the LAVH group, which was statistically significant $p$ value being $<0.0001$ (Table 8 and 9).

In a study by Sandhyasri $\mathrm{P}$ et al the mean duration of hospital stay in $\mathrm{AH}, \mathrm{VH}$ and LAVH group was 8days, 5.08 days and 4.78 days respectively. ${ }^{7}$

Similarly, in a study Radhika $Y$ et al it was found that the hospital stay was least with laparoscopic group (4days) as compared to abdominal (9.8days) and vaginal group (5.2days). ${ }^{9}$ Thus, the mean hospital stay is much longer in the AH group compared to other two groups.

\section{CONCLUSION}

Present study observes that LAVH allows visualisation of real anatomic picture in abdominal cavity, less blood loss, shorter hospital stay, smaller haemoglobin drop, less postoperative pain but has got longer operating time, long learning curve and higher cost of equipment. If setup, facilities and surgical expertise are available then LAVH can be offered as the first choice of route for hysterectomy, NDVH is done through natural orifice and thus there is avoidance of an abdominal wound which is a remarkable advantage and has shorter hospital stay and faster convalescence. In a developing country like India with poor health care resources, scarcity of beds and nonavailability of sophisticated equipment NDVH offers a distinct advantage over other route of hysterectomy and should be the route of choice for benign uterine conditions.

\section{Funding: No funding sources}

Conflict of interest: None declared

Ethical approval: The study was approved by the Institutional Ethics Committee

\section{REFERENCES}

1. Rock, John A. And Howard W. Jones III. Te Linde's Operative Gynecology. New Delhi: Wolters Kluwer (India) Pvt. Ltd., Eleventh edition. Chapter 32A, 697.

2. Asgari Z, Bahreini F, Samiee H, Eslami B, Tehranian A, Sabet S. Comparison of laparoscopically assisted vaginal hysterectomy and total abdominal hysterectomy. Med J Islamic Repub Iran (MJIRI). 2008;22(1):22-8.

3. Moradan S, Sayadjou S. Hospital based analysis of 204 cases of hysterectomies with evaluation of the route of surgery and complications rates. Southeast Asian J Case Report Review. 2014;3(6):1060-6.

4. Choosing the route of hysterectomy for benign diseases. ACOG Committee Opinion NO.444. American college of Obstetricians and Gynecologists. Obstet Gynecol. 2009;114:156-8.

5. Deshpande H, Burute S, Malik R. A comparative study of abdominal versus non descent vaginal hysterectomy. Int J Cont Med Res. 2016;3(4):1153-6.

6. Kovac R. Evidence based hysterectomy. Gynecol Obstet. 2013;3(1):e110.

7. Panda S, Behera AK, Jayalakshmi M, Rao TN, Indira G. Choosing the route of hysterectomy. J Obstet Gynecol India. 2015;65(4):251-4.

8. David-Montefiore E, Rouzier R, Chapron C, Darai E, Collegiale d'Obstétrique et Gynécologie de Paris-Ile de France. Surgical routes and complications of hysterectomy for benign disorders: a prospective observational study in French university hospitals. Human Reproduction. 2007;22(1):260-5.

9. Radhika Y, Gowthami D, Reddy JV, Rani. Merits and demerits of different houtes of hysterectomy for gynecological conditions without uterine descent. IOSR J Dental Med Sci. 2017;16(1):38-50.

10. Wright KN, Jonsdottir GM, Jorgensen S, Shah N, Einarsson JI. Costs and outcomes of abdominal, vaginal, laparoscopic and robotic hysterectomies. JSLS: J S Laparoendoscop Surg. 2012;16(4):519.

11. Mishra N, Thomas A, Misri A. Comparative study of laparoscopic and total abdominal hysterectomies. Academic Med J India. 2015;3(2).

12. De Reena, Goswami S. Acomparative study of Laparoscopically assisted vaginal hysterectomy and non-descent vaginal hysterectomy. J South Asian Fed Obstet Gynecol. 2014;6(2):101-3.

13. Elessawy M. Hysterectomy, a comparative study of the different Hysterectomy Routes 2002-2010: a retrospective analysis for 954 patients (Doctoral dissertation, Christian-Albrechts Universität Kiel).

14. McCracken G, Hunter D, Morgan D, Price JH. Comparison of laparoscopic-assisted vaginal hysterectomy, total abdominal hysterectomy and vaginal hysterectomy. Ulster Med J. 2006;75(1):54.

15. Schindlbeck C, Klauser K, Dian D, Janni W, Friese K. Comparison of total laparoscopic, vaginal and abdominal hysterectomy. Arch Gynecol Obstet. 2008;277:331-7.

16. Mirza R, Malhotra P, Kumar D, Kumar S. Abdominal versus vaginal hysterectomy in non-descent uterus. JK Sci. 2016;18(4).

Cite this article as: Uikey $P$, Wankhede TM, Tajne MP. The route of hysterectomy: a comparative study between abdominal hysterectomy (AH), non descent vaginal hysterectomy $(\mathrm{NDVH})$, and laparoscopic assisted vaginal hysterectomy (LAVH). Int J Reprod Contracept Obstet Gynecol 2018;7:4022-8. 